\title{
Molecular characterization of haemophilia A in southern Chinese
}

\author{
Vivian Chan, Annie Pang, T. P. T. Chan, V. Wan-Yin Chan and T. K. Chan \\ University Department of M edicine, Queen M ary Hospital, Hong Kong
}

Received 14 September 1995; accepted for publication 12 January 1996

\begin{abstract}
Summary 41 unrelated southern Chinese haemophilia A patients were studied. The $5^{\prime}$ promoter region, all 26 exons, their immediate $5^{\prime}$ and $3^{\prime}$ flanking splice junctions and the $3^{\prime}$ untranslated region of the FVIII gene were amplified (including 16 different segments of exon 14) using GCclamped primers. The GC-clamped PCR products were screened by denaturing gradient gel electrophoresis (DGGE) and fragments showing an abnormal migration pattern were

nonsense mutations and four frameshift mutations. 14 other patients carried the type 1 inversion, affecting the distal copy of the F8A gene at the telomere of the $X$ chromosomeand the same gene in intron 22 of the FVIII gene. All the mothers studied $(12 / 14)$ were carriers of the inversion. Two of these patients with inversion also have a co-existing missense mutation. In most cases the clinical severity of the disease corresponds to the genotype
\end{abstract} sequenced. 17 mutations were identified, of which four were splicing defects, involving the first 1- 6 nucleotide ( $n t)$ in the intervening sequences (IVS), six missense mutations, three

Keywords: FVIII, mutation, molecular pathology.

Haemophilia $A$ is the commonest $X$-linked congenital bleeding disorder, affecting approximately 1:30000 liveborn males. The incidence in South China is somewhat lower than in the Western world (Hong Kong Society of Haematology, 1982). Since the launch of a DNA prenatal diagnosis programme for this disorder in Hong Kong in 1987 we have encountered 41 unrelated haemophilia A families. Although it was possible to offer prenatal diagnosisin most cases using either the common restriction fragment length polymorphisms (RFLPs) such as Bcl I, Xba I/Kpn I and Taq I-St14 sites (Peake et al, 1993) or the intragenic microsatellite repeat polymorphisms in intron 13 and intron 22 (Lalloz et al, 1994; Yip et al, 1994) of the factor VIII (FVIII) gene, a direct analysis would be more accurate and can be used for sporadic cases or patients without informative families. Furthermore, characterization of the molecular defect will enable a better understanding of the structure-function relationship of the FVIII molecule.

Since the FVIII gene is $186 \mathrm{~kb}$ and contains 26 exons (Gitschier et al, 1984), a screening of possible mutations was made using denaturing gradient gel electrophoresis (DGGE) of polymerase chain reaction (PCR) amplified fragments containing the exons and their immediate $5^{\prime}$ and $3^{\prime}$ splice

Correspondence: Professor Vivian Chan, University Department of Medicine, Queen Mary Hospital, Hong Kong. junctions (Higuchi et al, 1991a, b). In addition, the inversion mechanism involving the two copies of the F8A intronless gene at the telomere of the $X$ chromosome and a copy of the same gene in intron 22 of the FVIII gene itself, was examined in all patients as a possiblegenetic lesion (Lakich et al, 1993).

\section{MATERIALS AND METHODS}

Forty-one unrelated haemophilia A patients and 51 carrier females from their families were studied. These females were either obligatory carriers or designated as a carrier based on DNA haplotype analysis with the common RFLPs such as Bcl I, Xba I/Kpn I, Taq I-St 14 and microsatellite repeat polymorphisms in intron 13 and 22. DNA was extracted from peripheral blood leucocytes and $1 \mu \mathrm{g}$ amounts used for PCR amplification of the different exons of the FVIII gene, using primers described by Higuchi et al (1991a). The PCR cycling conditions were: $94^{\circ} \mathrm{C} \times 2$ min followed by 32 cycles of denaturation at $94^{\circ} \mathrm{C} \times 1 \mathrm{~min}$, annealment at $50-60^{\circ} \mathrm{C}$ (depending on $\mathrm{Tm}$ of the primers) $\times 1 \mathrm{~min}$ and extension at $72^{\circ} \mathrm{C} \times 1 \mathrm{~min}$. Except for exons 18 and 24 which were amplified using thermo-cycle conditions, all the other fragments were amplified with a step-cycle procedure of the thermocycler (Perkin Elmer Cetus). PCR was performed in a total volume of $75 \mu \mathrm{l}$ in the presence of $200 \mu \mathrm{m}$ each of dNTP, 50 pm each of primers, $2.5 \mathrm{U}$ Taq polymerase, $1 \times$ Taq buffer 


\section{Vivian Chan et al}

(as recommended by the manufacturer, Perkin Elmer Cetus) and ampliwax. In addition, exon 14 was amplified as 16 different fragments, using a first-round PCR that encompassed the entire exon of $3.2 \mathrm{~kb}$, followed in each case by a second PCR (thermo-cycle) using $1.5 \mu \mathrm{l}$ of the initial PCR product as template.

The $5^{\prime}$ promoter region which spans from nucleotide (nt) -1175 to +14 (nt numbering according to Gitschier et al, 1984), was amplified in four different segments. The following primers were used: for promoter region 1 (PR1), $5^{\prime}$ PR1A ((GC)n, nt -1175 to -1155$)$ and $3^{\prime}$ PR $1 B$ (nt -847 to -826 ); PR2, 5' PR2A (nt -885 to -866 ) and $3^{\prime}$ PR2B ((GC)n, nt -655 to -636$)$; PR3, 5' PR3A ((GC)n, nt -715 to -696 ) and $3^{\prime}$ PR3B (nt -355 to -336 ) and PR4, 5' PR4A ((GC)n, nt -355 to -336 ) and $3^{\prime}$ PR4B (nt -7 to +14 ). The GC clamp sequence was the same as used by Higuchi et al (1991a). Nt 1-3 gives the start signal 'ATG' corresponding to codon -19 , the beginning of the signal peptide. The mature $\mathrm{N}$-terminusstarts at codon 1 (codon numbering according to Vehar et al, 1984).

In addition, part of the $3^{\prime}$ untranslated region, after exon 26, from nt 8364-9360 was amplified as three different segments. The following primers were used: region PA $1,5^{\prime}$ PA $1 A$ ((GC)n, nt 8364-8383) and $3^{\prime}$ PA $1 B$ (nt 8707-8726), region PA2, 5' PA2A (nt 8665-8686) and $3^{\prime}$ PA 2B ((GC)n, nt 9032-9055) and region PA3, 5' PA $3 A((G C) n$, nt 89819000) and 3' PA 3B (nt 9339-9360). These segments covered the polyadenylation signal at nt 8839-8850. The PCR conditions were as described above and amplification was made using 32 rounds of step cycle.

Denaturing gradient gel electrophoresis (DGGE). A fter amplification, samples were subjected to DGGE without further purification. $8 \mu \mathrm{l}$ of PCR product from the haemophiliac patient were incubated with an equal volume of the same PCR product from a normal female and subjected to one cycle of the following conditions: $94^{\circ} \mathrm{C} \times 6 \mathrm{~min}$, followed by rapid cooling to $65^{\circ} \mathrm{C}$ and then more gradual cooling to $25^{\circ} \mathrm{C}$ over $35 \mathrm{~min}$. The sample was then loaded onto denaturing gradient gel with $3 \mu \mathrm{l}$ of dye consisting $0.5 \%$ bromophenol blue, $20 \%$ sucrose in $10 \mathrm{~mm}$ Tris, $1 \mathrm{~mm}$ EDTA pH 7.8. Electrophoresis was performed at $60^{\circ} \mathrm{C}$ in $7 \%$ polyacrylamide gel containing a linear gradient of denaturant, using a constant voltage of $150 \mathrm{~V}$ for $5 \mathrm{~h}$ in $1 \times \mathrm{TAE}$ buffer $(20 \times \mathrm{TAE}=0.8 \mathrm{~m}$ Tris, $0.4 \mathrm{~m}$ sodium acetate, $0.02 \mathrm{~m}$ EDTA, $\mathrm{pH} 7 \cdot 4)$. The denaturing gradients used were determined, using the MELT 87 program of L. Lerman, by Kazazian and co-workers (personal communication, H. H. Kazazian, Jr) [ $80 \%$ denaturant stock $=5.6 \mathrm{~m}$ urea, $32 \%$ formamide (vol/ vol)]. Gels were then stained in ethidium bromide and photographed under UV light.

Sequence analysis. GC-clamped PCR fragments which showed an abnormal migration pattern on DGGE were purified on polyacrylamide gel and sequenced directly as described previously (Chan et al, 1989), using Sequenase Version 2 kit (United States Biochemicals, Ohio, U.S.A.), with non G-C-clamped primers as sequencing primers.

FVIII gene inversion. FVIII gene inversion involving the intronless F8A genes at the telomere of the $X$ chromosome and the single copy of the same gene within intron 22 of the
FVIII gene itself can be studied by Southern blotting. Bcl I digested genomic DNA from haemophilia $A$ patients and their female family members were electrophoresed in $0.8 \%$ agarose gel, transferred onto nitrocellulose or nylon filter and hybridized to ${ }^{32} \mathrm{P}$-labelled gene probe, which is a $1.1 \mathrm{~kb}$ EcoR I-Sst I fragment from plasmid p482.6 (Lakich et al, 1993).

\section{RESULTS}

After analysing the promoter region, all 26 exons as well as the $3^{\prime}$ untranslated region of the FVIII gene, possible diseaseproducing mutations were identified in 17/41 haemophiliac patients. When an abnormal migration pattern was detected in DGGE, the particular fragment was purified and direct sequencing was performed (Fig 1). The various types of mutations are listed in Table I. Unlike previous studies of haemophiliacsfrom Caucasian populations(Youssoufian et al, $1988)$, relatively few $(3 / 17)$ of the defects were due to CG transitions. Of these, two have been previously reported (Pattinson et al, 1990; Higuchi et al, 1991b; A ntonarakiset al, 1995). Other defects found included four in the exon/intron splice junctions, with one affecting the donor splice site between intron 6 and exon 7 (codon 244 GGT $\rightarrow$ AGT). Two unrelated haemophiliac patients had the same IVS-5 nt 6 defect ( $\rightarrow \mathrm{c}$ ). Four frameshift mutations were detected, three of which resulted in premature termination downstream. Two of these cases were due to deletion of one nucleotide, and the third to addition of one nucleotide. A fourth case of frameshift mutation involved the deletion of three nucleotides ( $\triangle A G G$, codon 390/391), resulting in loss of a glutamic acid. There were also three cases of nonsense mutation. Five missense mutations, including the CG transitions (CGT $\rightarrow$ CAT, Arg $\rightarrow$ His at codon $2150, \underline{G C T} \rightarrow$ ICT, Ala $\rightarrow$ Ser at codon 1591), the others are the Pro $\rightarrow$ A rg at codon 928, Glu $\rightarrow$ Lys at codon 1038 and a Ser $\rightarrow$ Leu at codon 170 which we have previously reported (Chan et al, 1989).

The silent polymorphism at codon 2223, Val $\rightarrow$ Met (Higuchi et al, 1991b) was identified in the normal chromosome of two carrier females.

\section{Screening for gene rearrangement (inversion)}

Fourteen patients had gene rearrangement involving inversion of intron 22 of the FVIII gene and the distal F8A gene at the telomere of the $X$ chromosome(type 1 inversion; Goodeve et al, 1994). Only 12 of the mothers were available for study and all were carriers of the inversion. In five families the grandparents were also studied, but the paternal origin of the gene inversion could be established in only three cases. DNA linkage using the common intragenic and extragenic RFLPS as well as the introns 13 and 22 microsatellite repeat polymorphisms had been used to characterize the haplotypes and ascertain the paternal or maternal origin of the various $X$ chromosomes in these families.

Two of the patients with this intron 22 gene inversion also have a missense mutation in exon 14 . Both of these mutations lie in the B domain, and the mutation of Glu $\rightarrow$ Lys at codon 1038 had previously been reported (Higuchi et al, 1991b). The 


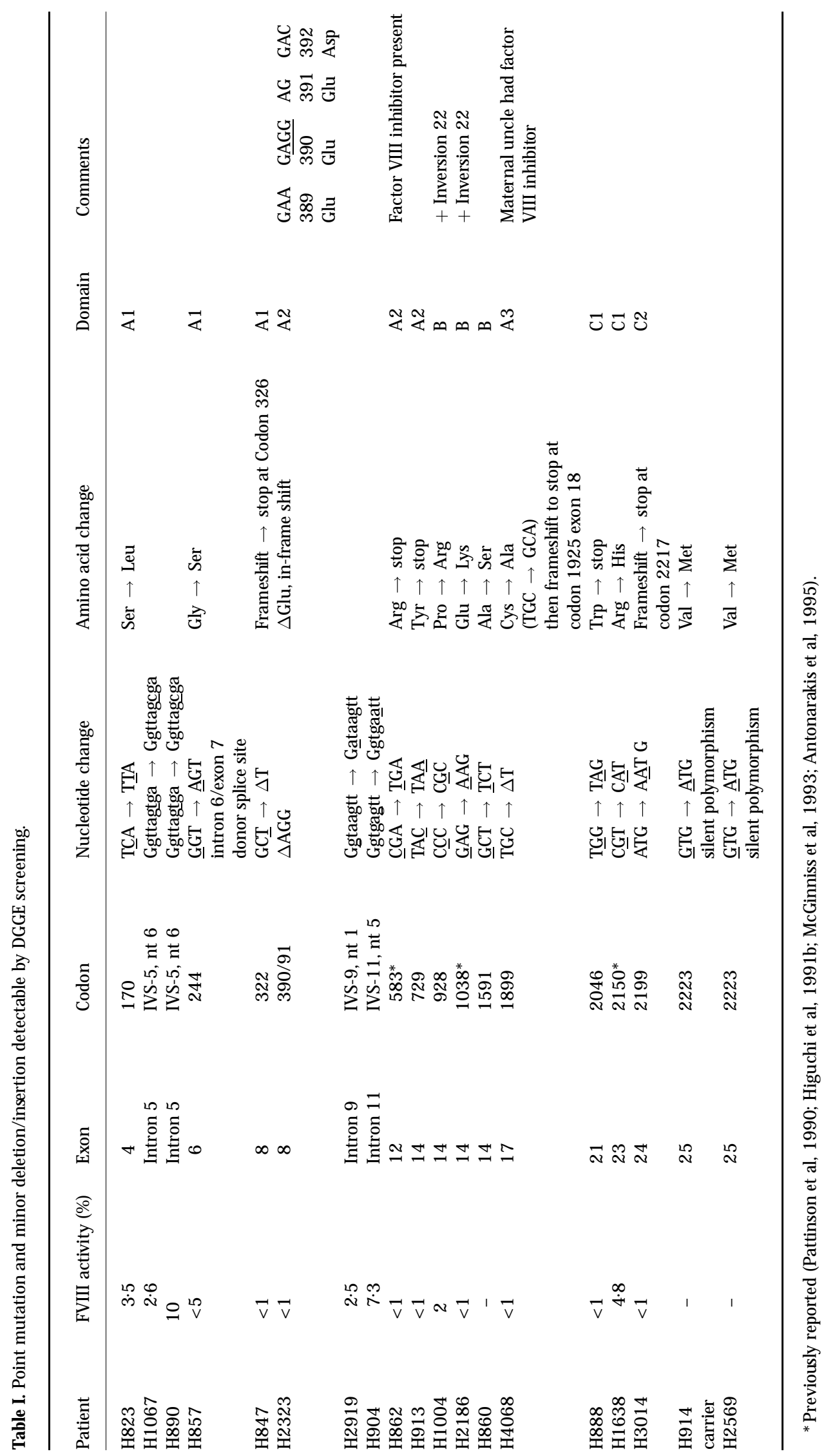


II

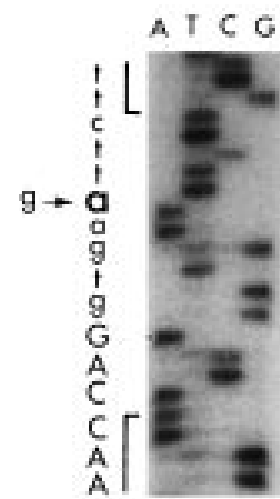

$M$

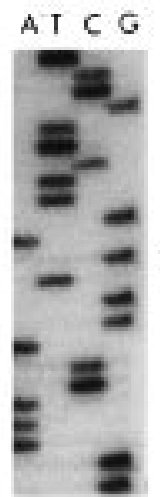

$N$

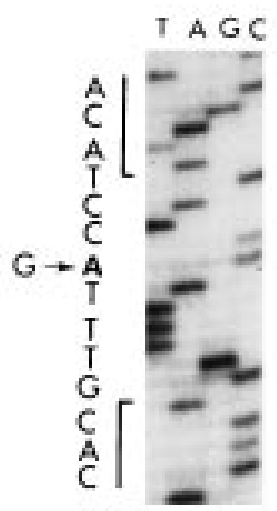

A

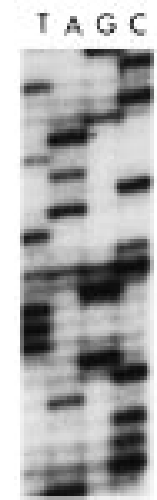

N

III

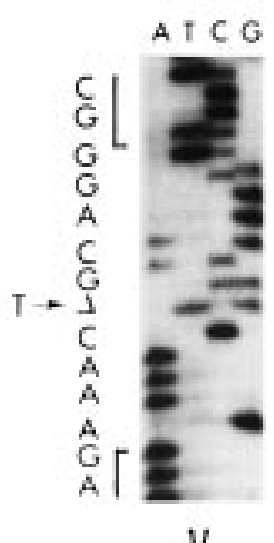

II

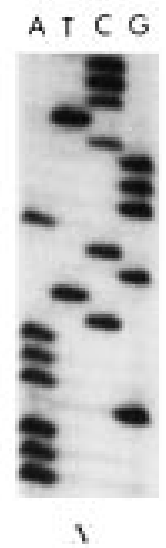

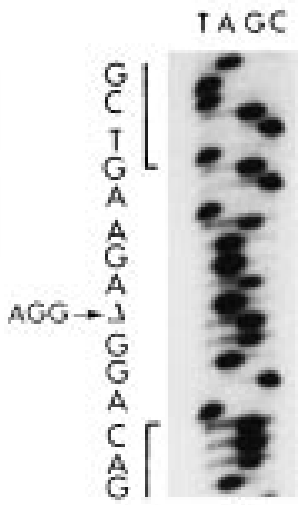

II
IV

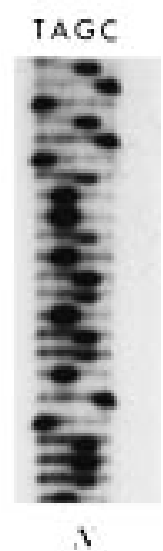

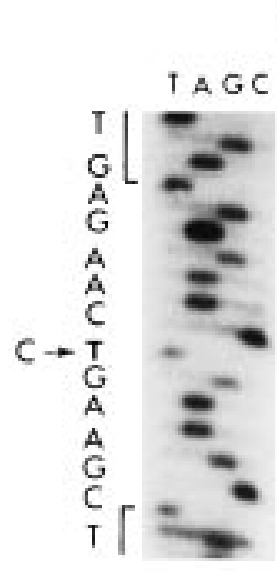

it
V

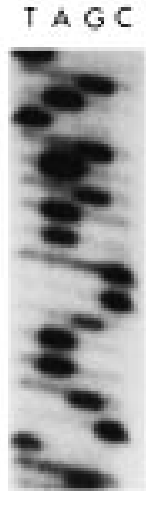

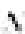

Fig 1. Direct genomic sequencing of PCR-amplified FVIII gene fragments around the mutation site, in haemophilia A patients (M) and a carrier female (M, panel III) compared to that in a normal male (N). Panel I, splice junction defect IVS 11, nt $5 \mathrm{~g} \rightarrow$ a; panel II, missense mutation, exon 23 , codon 2150 CGT $\rightarrow$ CAT, panel III, frameshift mutation, exon 17, codon 1899 TGC $\rightarrow \Delta T$; panel IV, frameshift mutation, exon 8 , codon $390 /$ $391 \Delta$ AGG; panel V, nonsensemutation, exon 12, codon 583 CGA $\rightarrow$ TGA. Sequencing in panels II, IV and V were madein the reverse strand with $3^{\prime}$ amplification primers. For convenience in reading the sequence, the sequencing lanes and the sequence have been reverse complemented.

second case involved a mutation at codon 928, Pro $\rightarrow$ Arg, and this patient has moderate disease (FVIII activity $2 \%$ ).

\section{DISCUSSION}

The molecular defects have been identified in 29/41 unrelated haemophilia A patients in this study. This group of patients consisted of the entire spectrum of severe, moderate and mild clotting deficiency. In a few cases there was no documentation of their FVIII level at diagnosis, because they were cases referred for prenatal diagnosis from Guangdong province of South China. In general, those with nonsense and frameshift mutations have severe FVIII deficiency (FVIII level $<1 \%$ ), and amongst them two cases, one in $\mathrm{A} 2$ domain and another in $\mathrm{A} 3$ domain, were known to have developed antibodies (inhibitors) after treatment with exogenous factor VIII. The five patients with defects affecting the intron/exon splice junction, including the case where the donor splicesite at intron 6 and exon 7 was mutated at codon
244 (Gly $\rightarrow$ Ser), have moderate to mild defects only. This is similar to $\beta$ thalassaemia, where defects in the IVS, especially those not within the first five nucleotides of the exon/intron junction, are known to give rise to $\beta^{+}$thalassaemia phenotype (Kazazian \& Boehm, 1988). It is also of interest to notethat except for the mutation at IVS-5, nt 6, none of the mutations have occurred twice within the 41 unrelated cases, despite the fact that all these patients originated from the same province in South China. Three of the defects (one nonsense and two missense mutations) have been reported in the literature elsewhere (Pattinson et al, 1990; Higuchi et al, 1991b; Antonarakis et al, 1995). In particular, the codon $2150 \mathrm{Arg} \rightarrow$ His has been documented in over 10 cases worldwide, in dicating that this is probably a mutation hotspot (Antonarakis et al, 1995). There is one frameshift mutation which involved the deletion of three nucleotides at codon $390 / 391(\Delta A G G)$, resulting in loss of one of the three glutamines in this region. Sincethis is an in-frame shift, it did not cause premature termination of mRNA translation. The 
Table II. Molecular defects in 41 haemophilia A families according to clinical severity.

\begin{tabular}{|c|c|c|c|c|c|}
\hline \multirow[b]{2}{*}{$\begin{array}{l}\text { Category } \\
\text { (severity) }\end{array}$} & \multirow[b]{2}{*}{$\begin{array}{l}\text { Factor VIII } \\
(\%)\end{array}$} & \multirow[b]{2}{*}{ Total } & \multicolumn{3}{|l|}{ Type of defects } \\
\hline & & & $\begin{array}{l}\text { Point mutation } \\
\text { or minor changes }\end{array}$ & $\begin{array}{l}\text { Inversion } \\
\text { intron } 22\end{array}$ & $\begin{array}{l}\text { Not } \\
\text { detected }\end{array}$ \\
\hline I. Mild & $>5$ & 8 & 4 & - & 4 \\
\hline II. Moderate & $1-5$ & 9 & 4 & $4 *$ & 1 \\
\hline Subtotal & & 17 & $8(47 \%)$ & $4(24 \%)$ & $5(29 \%)$ \\
\hline III. Severe & $<1$ & 24 & 7 (29\%) & $10 *(42 \%)$ & 7 (29\%) \\
\hline Total & & 41 & $15(37 \%)$ & $14(34 \%)$ & $12(29 \%)$ \\
\hline
\end{tabular}

* One with additional missense mutation in exon 14 .

resultant protein should only have one less amino acid. The sequence around codons 385-397 is relatively conserved in both murine and human FVIII as well as human FV and ceruloplasmin. It is therefore likely that this mutation is responsible for the severe FVIII deficiency in our patient, in keeping with other mutations in the $A 2$ domain, which is thought to be important for FVIII procoagulant activity (Lollar \& Parker, 1991).

There are three mutations in the $B$ domain, which is cleaved out on activation of FVIII. It is questionable whether mutations in this area are functionally important (Higuchi et al, 1991b; Antonarakiset al, 1995). In particular, since two of these mutationsalso occurred concurrently with the type 1 inversion of intron 22, they may well be rare polymorphisms, with no functional effect. Patient $\mathrm{H} 2186$ carried the inversion as well as a missense mutation at codon $1038 \mathrm{Glu} \rightarrow$ Lys. This particular missense mutation had been previously reported (Higuchi et al, 1991b; McGinniss et al, 1993) and thought to affect intracellular processing. The second patient, $\mathrm{H} 1004$, with moderate deficien cy, had coexistence of the gene inversion and a missense mutation at codon 928 (Pro $\rightarrow$ Arg). A third patient, $\mathrm{H} 860$, also had moderate deficiency and his only abnormality is a mutation at codon 1591 (Ala $\rightarrow$ Ser).

Previous reports of FVIII-intron 22 gene rearrangement were mainly in patients with severe clotting deficiencies (Lakich et al, 1993; Goodeve et al, 1994; Jenkins et al, 1994). In our 14 patients, four were known to have moderatedisease with FVIII level of $4 \%, 3.5 \%, 3.4 \%$ and $2 \%$ respectively (Table II). Of the two patients with concommittant exon 14 missense mutation and gene inversion, one had severe clotting deficiency and the other moderate deficiency. Analysis of mRNA is underway to determine the level of expression. All the rearrangements involved the distal copy of the F8A gene (Goodeve et al, 1994). Except for two cases in whom the mothers were not available for study, all the other mothers (12/14) were carriers of the inversion. It is likely that the origin of theinversion is from the maternal grandfather, in keeping with the belief that the inversion occurs predominantly in the male germ cells, as the single $\mathrm{Xq}$ region predisposes to flipping backwards onto itself during meiosis in the male (Rossiter et al, 1994).
The defect in 12 patients remains unknown: five with mild to moderate deficiency and seven with severe deficiency. We have used the same primers, GC clamp sequences and DGGE conditions as Higuchi et al (1991a) who were able to detect the majority of mild and moderate defects in the coding region and splice junctions of FVIII gene. We have also looked at the promoter and $3^{\prime}$ untranslated regions but found no abnormalities. As with the $\beta$ globin gene, the FVIII gene may well be controlled by $5^{\prime}$ locus control regions (LCR) or hypersensitive sites (HS) much further upstream from the gene itself. Further studies will be needed to determine if this explains the undefined molecular defect in the remaining cases, or if their defect lies further in the introns, which we have not sequenced, or in other trans-acting genes.

\section{ACKNOW LEDGMENTS}

The authors are indebted to Dr H. H. Kazazian, Jr and his coworkers for information on the DGGE conditions, Dr R. Lawn for p486.2, and the Croucher Foundation for financial support.

\section{REFERENCES}

Antonarakis, S.E., Kazazian, H.H., Jr \& Tuddenham, E.G.D. (1995) Molecular etiology of factor VIII deficiency in hemophiliaA. Human M utation, 5, 1-22.

Chan, V., Chan, T.K., Tong, T.M.F. \& Todd, D. (1989) A novel missense mutation in exon 4 of the factor VIII:C gene resulting in moderately severe hemophilia A. Blood, 74, 2688-2691.

Gitschier, J., Wood, W.I., Goralka, T.M., Wion, K.L., Chan, E.Y., Eaton, D.H., Vehar, G.A., Capon, D.J. \& Lawn, R.M. (1984) Characterization of the human factor VIII gene. Nature, 312, 326-330.

Goodeve, A.C., Preston, F.E. \& Peake, I.R. (1994) Factor VIII gene rearrangements in patients with severe haemophilia $A$. Lancet, 343, 329-330.

Higuchi, M., Antonarakis, S.E., Kasch, L., Oldenburg, J., EconomouPetersen, E., Olek, K., Arai, M., Inaba, H. \& Kazazian, H.H., Jr (1991a) Molecular characterization of mild-to-moderate hemophilia A: detection of the mutation in 25 of 29 patients by denaturing gradient gel electrophoresis. Proceedings of the National A cademy of Sciences of the United States of America, 88, 8307-8311.

Higuchi, M., Kazazian, H.H., Jr, Kasch, L., Warren, T.C., McGinniss, 


\section{Vivian Chan et al}

M.J., Phillips, J.A., III, Kasper, C., Janco, R. \& Antonarakis, S.E. (1991b) Molecular characterization of severe hemophilia A suggests that about half the mutations are not within the coding regions and splice junctions of the factor VIII gene. Proceedings of the National A cademy of Sciences of the United States of America, 88, 7405-7409.

Hong Kong Society of Haematology (1982) Haemophilia Committee report.

Jenkins, P.V., Collins, P.W., Goldman, E., McCraw, A., Ridell, A., Lee C.A. \& Pasi, K.J. (1994) Analysis of intron 22 inversions of the factor VIII gene in severe hemophilia A: implications for genetic counselling. Blood, 84, 2197-2201.

Kazazian, H.H., Jr \& Boehm, C.D. (1988) Molecular basis and prenatal diagnosis of $\beta$-thalassemia. Blood, 72, 1107-1116.

Lakich, D., Kazazian, H.H., Jr, Antonarakis, S.E. \& Gitschier, J. (1993) Inversions disrupting the factor VIII gene as a common cause of severe haemophilia A. Nature Genetics, 5, 236-241.

Lalloz, M.R.A., Schwaab, R., McVey, J.H., Michaelides, K. \& Tuddenham, E.G.D. (1994) Haemophilia A diagnosis by simultaneous analysis of two variable dinucleotide tandem repeats within the factor VIII gene. British Journal of Haematology, 86, 804-809.

Lollar, P. \& Parker, E.T. (1991) Structural basis for the decreased procoagulant activity of human factor VIII compared to the porcine homology. Journal of Biological Chemistry, 226, 12481-12486.

McGinniss, M.J., Kazazian, H.H., Jr, Hoyer, L.W., Bi, L., Inaba, H. \& Antonarakis, S.E. (1993) Spectrum of mutations in CRM-positive and CRM-reduced hemophilia A. Genomics, 15, 392-398.

Pattinson, J.K., Millar, D.S., McVey, J.H., Grundy, G.B., Wieland, K., Mibashan, R.S., Martinowitz, U., Tan-Un, K., Vidaud, M.,
Gossens, M., Sampietro, M., Mannucci, P.M., Krawczak, M., Reiss, J., Zoll, B., Whitmore, D., Bowcock, S., Wensley, R., Ajani, A., Mitchell, V., Rizza, C., Maia, R., Winter, P., Mayne, E.E., Schwartz, M., Green, P.J., Kakkar, V.V., Tuddenham, E.G.D. \& Cooper, D.N. (1990) The molecular genetic analysis of hemophilia A: a directed search strategy for the detection of point mutations in the human factor VIII gene. Blood, 76, 2242-2248.

Peake, I.R., Lillicrap, D.P., Boulyjenkov, V., Briet, E., Chan, V., Ginter, E.K., Kraus, E.M., Ljung, R., Mannucci, P.M., Nicolaides, K. \& Tuddenham, E.G.D. (1993) Report of a joint WHO/WFH meeting on the control of haemophilia: carrier detection and prenatal diagnosis. Blood Coagulation and Fibrinolysis, 4, 313-344.

Rossiter, J.P., Young, M., Kimberland, M.L., Hutter, P., Ketterling, R.P., Gitschier, J., Horst, J., Morris, M.A., Schaid, D.J., de Moerloose, P., Sommer, S.S., Kazazian, H.H., Jr \& Antonarakis, S.E. (1994) Factor VIII geneinversionscausing severe haemophilia A originatealmost exclusively in male germ cells. Human M olecular Genetics, 3, 10351039.

Vehar, G.A., Keyt, B., Eaton, D., Rodriguez, H., O‘Brien, D.P., Rotblat, F., Oppermann, H., Keck, R., Wood, W.I., Harkins, R.N., Tuddenham, E.G.D., Lawn, R.M. \& Capon, D.J. (1984) Structure of human factor VIII. Nature, 312, 337-342.

Yip, B., Chan, V. \& Chan, T.K. (1994). Intragenic dinucleotiderepeats in factor VIII gene for the diagnosis of haemophilia A. British Journal of Haematology, 88, 889-891.

Youssoufian, H., Antonarakis, S.E., Bell, W., Griffin, A.M. \& Kazazian, H.H., Jr (1988) Nonsense and missense mutation in hemophilia $A$ : estimate of the relative mutation rate at CpG dinucleotides. American Journal of Human Genetics, 42, 718-725. 